\title{
USO DE CEPILHO COMO SUBSTRATO PARA CULTIVO SEMI- HIDROPÔNICO DE Cucumis melo
}

Miquéias TAGLIARI ${ }^{1}$

Francielli GASPAROTTO

Thais de Oliveira Iácono RAMARI ${ }^{3}$

\begin{abstract}
${ }^{1}$ Acadêmico do Curso de Agronomia da Unicesumar. miqueiasagron @ hotmail.com
${ }^{2}$ Professora do Mestrado em Tecnologias Limpas e do Curso de Graduação em Agronomia da Unicesumar. Atua na área de Fitopatologia, Microbiologia e Uso de Resíduos. francipg@gmail.com
\end{abstract}

${ }^{3}$ Professora do Curso de Graduação em Agronomia da Unicesumar e Mestranda do Curso de Tecnologias Limpas. thaisiacono@yahoo.com.br

Recebido em: 22/12/2015 - Aprovado em: 17/07/2016 - Disponibilizado em: 18/12/2016

\begin{abstract}
RESUMO: O objetivo deste trabalho foi avaliar o uso do cepilho como substrato para cultivo de melão rendilhado em sistema semi-hidropônico. O experimento foi desenvolvido em estufa plástica com três tratamentos: S1, S2 e S3 (areia, cepilho e solo agricultável, respectivamente). Utilizou-se o híbrido Sunrise, cultivado em vasos plásticos preenchidos com os substratos e fertirrigado por gotejamento. O delineamento experimental foi o inteiramente casualizado (três tratamentos e trinta repetições/tratamento). Avaliou-se o desenvolvimento das plantas, características dos frutos e severidade de podridão gomosa. Os substratos solo agricultável e cepilho não diferiram entre si quanto ao desenvolvimento das plantas, mas diferiram do substrato areia aos 28 dias após o transplante. Quanto aos frutos, não houve diferenças significativas entre os tratamentos. O substrato onde as plantas apresentaram menores lesões de podridão gomosa foi o cepilho. Todos os substratos avaliados se mostraram boas opções para cultivo do meloeiro rendilhado, porém o cepilho destacou-se por ser um material leve, além de manter a qualidade e produção.
\end{abstract}

Palavras-chave: Meloeiro. Cultivo protegido. Maravalha. Características dos frutos. Resíduo.

\begin{abstract}
The objective of this study was to evaluate the use of the shaver as a substrate for muskmelon cultivation in semi-hydroponic system. The experiment was conducted in greenhouse with three treatments: S1, S2 and S3 (sand, shaver and arable soil, respectively). The hybrid used was Sunrise, cultivated in plastic pots filled with substrates and fertirrigated drip. The experimental design was completely randomized (three treatments and thirty repetitions / treatment). The development was evaluated from plants, fruit characteristics and severity of gummy rot. The arable soil substrates and shaver did not differ as to the development of the plants, but differed from the substrate sand at 28 days after transplantation. As for fruit, there were no significant differences between treatments. The substrate where the plants had lower gummy rot lesions was the shaver. All evaluated substrates proved to be good choices for cultivation of melon tracery, but the shaver stood out for being a lightweight material and to maintain the quality and production.
\end{abstract}

Keywords: Melon. Greenhouse. Shavings. Characteristic of fruits. Residue.

\section{INTRODUÇÃO}

O melão é uma das frutas mais consumidas e exportadas pelo Brasil (AGRIANUAL, 2015) e o melão amarelo ainda é o mais consumido no país, mas o melão rendilhado vem ganhando espaço no mercado brasileiro em função da qualidade de seus frutos (PELIZZA, 2013).

Por se tratar de uma cultura de ciclo vegetativo curto e sensível as condições ambientais, torna-se necessário um controle destas para garantir nível adequado de 
produtividade. Assim, o cultivo em ambiente protegido proporciona boas condições para a produção, gerando frutos com melhor sabor, aspecto visual e altas produtividades (PADUAN et al., 2007; MELO et al., 2014).

Segundo Bezerra (2003) o cultivo protegido apresenta inúmeras vantagens como menor contaminação por fitopatógenos, maior precocidade e maior facilidade nos tratos culturais. No entanto, o uso intensivo do solo pode acarretar na salinização do meio (BLANCO; FOLEGATTI, 2001), assim como o manejo e o uso de tecnologia inadequada ao cultivo condiciona o desenvolvimento de doenças que causam danos significativos na produção (MELO et al., 2014).

Dentre as doenças incidentes nesta cultura, a podridão gomosa (Didymella bryoniae) assume posição de destaque limitando o cultivo de melão nas regiões de clima úmido (KUROZAWA, 2005) e com alta taxa de infecção latente podendo resultar em epidemia severa em ambientes de cultivo protegido (GASPAROTTO et al., 2011).

Como forma de prevenção da deterioração do solo e da contaminação por fitopatógenos em ambiente protegido tem-se utilizado o cultivo em vasos preenchidos com substratos, em um sistema semi-hidropônico, que influencia diretamente na produtividade e na qualidade dos frutos, atendendo todas as necessidades da planta, além de facilitar o controle na disseminação de doenças por meio da remoção do vaso e planta contaminados antes que se instale uma epidemia (VIDA et al., 1994; ANDRIOLO et al., 1999; CHARLO et al., 2009).

Existem diversas opções de substratos que podem ser utilizados na produção de mudas como também na condução de culturas. Muitos autores têm concentrado seus estudos em diferentes tipos de substratos como a fibra da casca de coco, areia, húmus, vermiculita, serragem de madeira, cama de aviário e a mistura em diferentes proporções entre esses e outros materiais (CHARLO et. al., 2011; MELO et al., 2012; SILVA et. al., 2013; BRUGNARA, 2014; MELO et al., 2014).

Uma vertente nas pesquisas com desenvolvimento de mudas e cultivo de plantas é a utilização de substratos oriundos da reutilização de resíduos orgânicos do setor agroindustrial, visto que são materiais biodegradáveis e com valor considerável em nutrientes (MARAGNO et al., 2007). Os processos de reutilização e reaproveitamento de resíduos economizam recursos naturais e reduzem os impactos ambientais quando comparados aos processos que utilizam matérias-primas virgens (SCHNEIDER, 2013). No entanto, para que a utilização desses resíduos seja viável é preciso que os mesmos não interfiram negativamente na produtividade e estejam disponíveis na região de cultivo.

O cepilho, ou maravalha é um resíduo gerado em grandes quantidades nas 
instalações de serraria em diversas regiões do país e pode ser reutilizado de diferentes maneiras, como na produção de carvão de lascas de eucalipto (SANTIAGO, 2005), na produção de chapas de partículas de madeira (VIDAURRE, 2004), na produção de aves como cama de frango (ÁVILA, 2007) e na composição de substratos para produção de mudas (CORRIJO, 2004).

Objetivou-se com este trabalho avaliar o uso do cepilho como substrato para cultivo de melão em sistema semi-hidropônico.

\section{MATERIAL E MÉTODOS}

$\mathrm{O}$ experimento foi realizado, junto à área experimental do Departamento de Agronomia, do Centro Universitário de Maringá-Unicesumar, no município de Maringá - PR.

$\mathrm{O}$ delineamento experimental foi inteiramente casualizado, em que foram avaliados três tratamentos e 30 repetições. Os tratamentos utilizados foram constituídos pelos seguintes substratos: areia lavada (S1), cepilho (S2) e solo agricultável (S3). Sendo utilizadas sementes comerciais do híbrido de melão rendilhado Sunrise.

Para a formação das mudas, foi realizado o sistema de semeadura indireta, sendo colocadas as sementes em gerbox na câmara úmida por 48 horas à $28^{\circ} \mathrm{C}$. Após a germinação as sementes foram plantadas em bandejas de 120 células preenchidas com substrato comercial. As bandejas foram acondicionadas em casa de vegetação, recebendo irrigação a cada quatro horas por um período de dez minutos por meio de microaspersores.

Quando as plantas apresentaram a primeira folha definitiva totalmente expandida, foi feito o transplante para vasos plástico de $10 \mathrm{dm}^{3}$ contendo cada um dos substratos testados. Em cada vaso foi transplantada uma muda, e os vasos foram alinhados no espaçamento de $0,5 \mathrm{~m}$ entre vasos e $1 \mathrm{~m}$ entre fileiras dentro da estufa plástica modelo em arco, coberta com polietileno de alta densidade $(100 \mu \mathrm{m})$.

$\mathrm{Na}$ instalação e condução da cultura foram empregadas as técnicas recomendadas por Brandão Filho e Vasconcellos (1998). As plantas foram conduzidas com haste única, tutoradas na vertical, com fitilho plástico sendo retirados todos os brotos até o décimo primeiro entrenó, para melhor condução da planta e reduzir a competição de luminosidade. Nos entrenós $12^{\circ}, 13^{\circ}$, e $14^{\circ}$ foram deixadas as hastes secundárias, onde foram formadas as flores/frutos. Nestas hastes foram retirados todos os brotos que surgiram e uma poda foi realizada na folha após o fruto. Nos próximos entrenós do caule continuou-se a retirar todos os brotos até o vigésimo. Nos entrenós $21^{\circ}, 22^{\circ}, 23^{\circ}$ foi deixado crescer a haste secundária e então se realizou a capação da planta. Nestas hastes secundárias foi deixado crescer uma nova brotação em cada uma delas (hastes terciarias), uma folha após 
o surgimento desta haste terciaria realizou-se a capação (corte do ápice da planta). Estas três hastes terciárias tiveram crescimento livre. Ao final, foram deixadas, por planta, apenas duas hastes secundárias, com um fruto por haste por planta. E ao atingirem a maturidade fisiológica os frutos foram envolvidos em uma rede para evitar queda e danos mecânicos nos mesmos.

Os tratos culturais foram realizados de acordo com as necessidades da cultura. A fertirrigação foi realizada por meio de gotejadores e a solução nutritiva utilizada foi composta por: $1.053 \mathrm{~g}$ de Nitrato de Cálcio (N-nítrico 14,5\%; N-amonical 1\%; e Ca 19\%), 500g de Sulfato de Magnésio (Mg 9\% e S 11\%); $217 \mathrm{~g}$ de MKP $\left(\mathrm{K}_{2} \mathrm{O} 34 \%\right) ; 700 \mathrm{~g}$ de Sulfato de Potássio $\left(\mathrm{K}_{2} \mathrm{O} 50 \%\right.$ e S 17\%); 30g de Micros Standard (Mo 0,36\% e Ni 0,335\%).

A colheita foi realizada quando os frutos apresentaram a camada de abscisão no pedúnculo, sendo coletados, identificados e levados ao laboratório para avaliações, foram colhidos cinco frutos por parcela.

O desenvolvimento vegetativo das plantas em cada substrato foi avaliado pela medida do tamanho das mesmas $(\mathrm{cm})$ a cada 7 dias. A severidade de podridão gomosa foi estimada ao final do experimento, por meio das medidas do maior comprimento longitudinal e perpendicular da lesão em cada planta, constituindo a área média em centímetros quadrados.
Os frutos foram aferidos quanto ao rendilhamento da casca pela metodologia adotada por RIZZO (2004); a massa fresa média dos frutos (MF) (g); produtividade (t/ha); diâmetro médio transversal e longitudinal do fruto (DMT e DML) (mm); o índice de formato do fruto (IFF) (PADUAN et. al, 2007) em que IFF $=1$ frutos com formato arredondado, IFF = 1,1 a 1,7 frutos oblongos ou alongados e IFF $<1,0$ frutos achatados (MELO et. al, 2012). Quanto às características organolépticas foram avaliados o teor de sólidos solúveis (SS) ( $\left.{ }^{\circ} \mathrm{Brix}\right)$ e o pH.

Os resultados de cada variável foram submetidos à análise de variância, e as médias foram comparadas pelo teste de Tukey, com nível de $5 \%$ de probabilidade.

\section{RESULTADOS E DISCUSSÃO}

As curvas de crescimento vegetativo das plantas de melão nos diferentes tratamentos mantiveram o mesmo padrão nos diferentes substratos e podem ser observadas na Figura 1.

As médias de crescimento vegetativo aferidas aos 14 e 21dias após o transplante não tiveram diferença estatística entre si (Tabela 1). Aos 28 dias após o transplante, os tratamentos S3 e S2 destacaram-se, e não tiveram diferença estatística entre si. Porém, diferiram significativamente do tratamento $\mathrm{S} 1$ que apresentou uma menor altura média de plantas. 


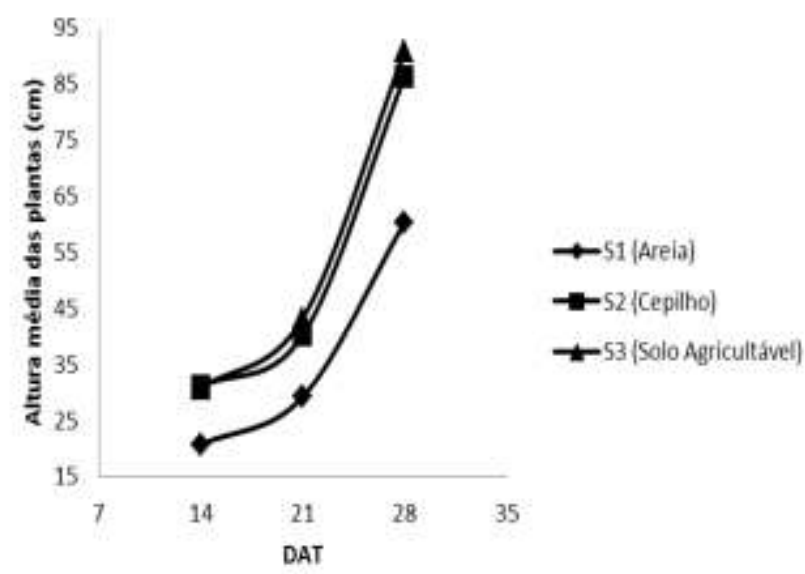

Figura 1. Crescimento vegetativo de plantas de melão híbrido Sunrise em três diferentes substratos: areia, cepilho e solo agricultável. Em que DAT: Dias após o transplante.

A média de desenvolvimento diário das plantas em cada substrato foi de $5,26 \mathrm{~cm}, 7,5$ $\mathrm{cm}$ e 7,84 $\mathrm{cm}$, para os substratos areia, cepilho e solo. Assim, tanto o solo agricultável como o cepilho obtiveram melhor desempenho que a areia pura.

Tabela 1. Médias de crescimento vegetativo $(\mathrm{cm}) \mathrm{de}$ plantas de meloeiro rendilhado híbrido Sunrise em diferentes substratos.

\begin{tabular}{lccc}
\hline Substratos(S) & $\begin{array}{c}\text { 14 dias } \\
(\mathbf{c m})\end{array}$ & $\begin{array}{c}\mathbf{2 1 ~ d i a s} \\
(\mathbf{c m})\end{array}$ & $\begin{array}{c}\mathbf{2 8 ~ d i a s} \\
(\mathbf{c m})\end{array}$ \\
\hline $\mathbf{S 1}^{1}$ & $20,7 \mathrm{a}^{2}$ & $29,2 \mathrm{a}$ & $60,6 \mathrm{a}$ \\
$\mathbf{S 2}$ & $31,1 \mathrm{a}$ & $40.2 \mathrm{a}$ & $86,3 \mathrm{~b}$ \\
$\mathbf{S 3}$ & $30,8 \mathrm{a}$ & $43,1 \mathrm{a}$ & $90,8 \mathrm{~b}$
\end{tabular}

${ }^{1}$ S1 - Substrato areia; S2 - Substrato cepilho; S3 Substrato solo de campo.

${ }^{2}$ Médias seguidas pela mesma letra na coluna não diferem entre si pelo teste de Tukey $(\mathrm{p}<0,05)$.

Resultados que convergem com os obtidos por Melo (2014) que verificou que a adição de casca de amendoim à areia, usada como substrato no cultivo de melão rendilhado no sistema semi-hidropônico, não interferiu na fisiologia de crescimento da cultura.

Quanto à sanidade da cultura, foi observada no experimento a incidência de podridão gomosa (Didymella bryoniae) em todos os tratamentos. Seu desenvolvimento ocorreu de forma natural, com o inoculo provavelmente originário das sementes do híbrido Sunrise utilizadas para o experimento. Gasparotto et al. (2009) detectou associações entre o patógeno Didymella bryoniae e sementes do híbrido Sunrise superiores a $50 \%$.

O início dos sintomas da podridão gomosa coincidiu com a senescência das folhas cotiledonares das plantas em todos os substratos avaliados, porém as médias de severidades da doença apresentaram diferença estatística entre os tratamentos S2 e S3 (Tabela 2). O tratamento em que a doença apresentou maior severidade foi o referente ao substrato solo agricultável, valores intermediários foram observados no tratamento $\mathrm{S} 1$ e o tratamento onde a doença ocorreu com menor severidade foi o que utilizou-se o cepilho como substrato.

Penharbel (2011) verificou que o cultivo de meloeiro nobre em condições hidropônicas proporciona uma menor severidade e intensidade de podridão gomosa em relação ao plantio convencional no solo. Neste trabalho, que foi desenvolvido no sistema semi-hidropônico, as plantas cultivadas no substrato solo agricultável 
apresentaram maior severidade da doença, o que indica uma menor severidade de podridão gomosa em culturas conduzidas em outros substratos do que em solo.

Tabela 2. Severidade de podridão gomosa (Didymella bryoniae) $\left(\mathrm{cm}^{2}\right)$ em plantas de meloeiro nobre híbrido Sunrise produzidas em diferentes substratos de plantio.

\begin{tabular}{lc}
\hline Substratos & Severidade $\left(\mathbf{c m}^{\mathbf{2}}\right)$ \\
\hline $\mathrm{S} 1{ }^{1}$ & $11,04 \mathrm{ab}^{2}$ \\
$\mathrm{~S} 2$ & $7,46 \mathrm{~b}$ \\
$\mathrm{~S} 3$ & $13,06 \mathrm{a}$ \\
\hline $\mathbf{C V}(\boldsymbol{\%})$ & $\mathbf{1 6 , 4 3 \%}$ \\
\hline${ }^{1} \mathrm{~S} 1-$ Substrato areia; S2 - Substrato cepilho; S3 - \\
Substrato solo de campo. \\
${ }^{2}$ Médias seguidas pela mesma letra na coluna não \\
diferem entre si pelo teste de Tukey (p<0,05).
\end{tabular}

Não houve diferença estatística para a qualidade de renda nos frutos nos diferentes tratamentos (Tabela 3), porém, os frutos que apresentaram melhores notas foram os produzidos nos tratamentos $\mathrm{S} 1$ e $\mathrm{S} 2$. Da mesma forma, Vargas et al. (2008a) verificaram que os frutos produzidos no solo apresentaram rendilhamento menos intenso comparado com os frutos produzidos em substrato fibra de coco.

Não foram encontradas diferenças significativas para os diâmetros transversais e longitudinais dos frutos produzidos em cada um dos substratos testados (Tabela 3). Em relação ao IFF observa-se que em todos os tratamentos os frutos tenderam a um formato arredondado. Mas apenas os frutos produzidos pelo substrato cepilho se aproximaram das exigências do sistema de padronização interna e externa (ARAÚJO et. al, 1999) e ficaram com índice mais próximo do intervalo de 1,05 e 1,11.

Tabela 3. Valores médios das características dos frutos de melão rendilhado híbrido Sunrise produzidos em diferentes substratos:

\begin{tabular}{lcccccccc}
\hline \multicolumn{1}{c}{ Substratos } & $\mathrm{RC}^{1}$ & $\begin{array}{c}\mathrm{DTF} \\
(\mathrm{mm})\end{array}$ & $\begin{array}{c}\mathrm{DLF} \\
(\mathrm{mm})\end{array}$ & IFF & $\begin{array}{c}\text { MF } \\
(\mathrm{g})\end{array}$ & $\begin{array}{c}\text { Prod. } \\
\left(\mathrm{t} . \mathrm{ha}^{-1}\right)\end{array}$ & $\begin{array}{c}\mathrm{SS} \\
\left({ }^{\circ} \mathrm{Brix}\right)\end{array}$ & $\begin{array}{c}\mathrm{pH} \\
\left(\mathrm{H}^{+}\right)\end{array}$ \\
\hline $\mathrm{S} 1^{2}$ & $2,42 \mathrm{a}$ & $99,9 \mathrm{a}$ & $98,8 \mathrm{a}$ & 0,99 & $732 \mathrm{a}$ & $29,31 \mathrm{a}$ & $11,55 \mathrm{a}$ & $6,62 \mathrm{a}$ \\
$\mathrm{S} 2$ & $2,42 \mathrm{a}$ & $101,0 \mathrm{a}$ & $103,6 \mathrm{a}$ & 1,03 & $755 \mathrm{a}$ & $30,16 \mathrm{a}$ & $11,31 \mathrm{a}$ & $6,62 \mathrm{a}$ \\
$\mathrm{S} 3$ & $2,28 \mathrm{a}$ & $100,3 \mathrm{a}$ & $115,9 \mathrm{a}$ & 1,16 & $791 \mathrm{a}$ & $31,64 \mathrm{a}$ & $11,22 \mathrm{a}$ & $6,59 \mathrm{a}$ \\
\hline $\mathrm{CV}(\%)$ & 29,46 & 4,64 & 29,46 & & 19,49 & 5,85 & 15,83 & 2,06 \\
\hline
\end{tabular}

${ }^{1}$ rendilhamento da casca (RC), massa fresca dos frutos (MF), diâmetro transversal do fruto (DTF), diâmetro longitudinal dos frutos (DLF), índice de formato do fruto (IFF), Produtividade (Prod.) e SS (sólidos solúveis).

${ }^{2}$ S1 - Substrato areia; S2 - Substrato cepilho; S3 - Substrato solo de campo.

${ }^{3}$ Médias seguidas pela mesma letra na coluna não diferem entre si pelo teste de Tukey $(\mathrm{p}<0,05)$.

Melo (2012) encontrou valores de IFF menores que os encontrados neste trabalho para melão rendilhado 'Fantasy', cultivado em substrato comercial sob cultivo protegido. De acordo com Padua et. al (2003), o IFF é relevante na disposição dos frutos em embalagens a fim de facilitar o transporte ou armazenamento e o mais adequado são frutos com formato arredondado, convergindo com os resultados obtidos neste trabalho.

A massa média dos frutos $(\mathrm{g})$ foi avaliada ao final do ciclo da cultura e também 
não apresentou diferenças significativas entre os tratamentos avaliados (Tabela 03). Os frutos resultantes do tratamento cujo substrato foi areia apresentaram a menor média absoluta de massa fresca, porém foram os que apresentaram o maior teor de sólidos solúveis. Esta relação entre menor massa fresca e maior teor de SS também foi constatada por Charlo et al. (2011) com o híbrido Fantasy cultivado em substrato composto por fibra da casca de coco.

A massa dos frutos de melão rendilhado aliada as características de sabor e aroma pode ser considerada muito importante na eleição de um híbrido (FACTOR, 2000). O mercado externo tem preferência por frutos pequenos a médios, com peso variando de 0,8 $\mathrm{kg}$ a 1,5 kg, segundo SOUZA et al. (1999). No presente trabalho podemos observar que os frutos produzidos nos diferentes substratos estão próximos aos valores de exportação conforme a massa fresca de frutos apresentados na Tabela 03.

Não houve diferenças significativas para a produtividade nos diferentes tratamentos (Tabela 03), sendo que esta ficou próxima a 30 t.ha $^{-1}$. Vargas et al. (2008a), obteve produtividade média de 50,2 t/ha de meloeiro rendilhado produzido com o substrato fibra de casca de coco. Esta diferença, provavelmente, está relacionada a época de condução dos experimentos, pois os autores cultivaram o meloeiro no verão onde os dias são mais longos com maior luminosidade,

favorecendo

o

desenvolvimento das plantas, proporcionando maior produtividade, em comparação com este experimento desenvolvido no outono/inverno.

Para sólidos solúveis, não foi verificado diferença estatística significativa entre os tratamentos e os valores médios ficaram ao redor de $11^{\circ}$ Brix. Diversos fatores relacionados com o ambiente e os tipos de manejo interferem no teor de sólidos solúveis dos frutos como a temperatura, fotoperíodo, área foliar, aplicação de fertilizantes, manejo da irrigação, entre outros (SILVA et. al, 2002).

De acordo com Filgueira (2008) a redução do teor de sólidos solúveis nos frutos tem relação direta com o excesso de água nos substratos. Em estudo de desenvolvimento de melão rendilhado em diferentes substratos, Charlo (2009) observou que não houve diferença significativa entre os teores de sólidos solúveis encontrados nos melões cultivados em substratos compostos de $100 \%$ de fibra da casca de coco, $50 \%$ areia $50 \%$ casca de amendoim e, 100\% areia. Porém, numericamente o menor teor foi resultante do substrato $100 \%$ areia, que, segundo o autor pode ter relação direta com a capacidade de retenção de água entre eles. Esses resultados diferem dos resultados encontrados neste trabalho, em que o maior ${ }^{0}$ Brix de forma absoluta foi obtido nos frutos oriundos do substrato $100 \%$ areia. 
De acordo com Rizzo e Braz (2004) são considerados excelentes para exportação frutos com ${ }^{\circ}$ Brix entre 12-15; próximo de $9^{\circ}$ Brix os frutos são considerados aceitáveis e, abaixo desse valor não são comercializáveis. Assim, os valores encontrados neste experimento se aproximam de 12 e são, portanto considerados aceitáveis.

Os valores médios de $\mathrm{pH}$ da polpa dos frutos detectados neste estudo foram 6,62; 6,62 e 6,59 para os tratamentos $S 1, S 2$ e $S 3$, respectivamente (Tabela 3), sendo estes resultados semelhantes aos encontrados por outros autores (CASTOLDI et al., 2008; VARGAS et al., 2008b; CHARLO et al., 2009).

Os substratos cepilho e solo agricultável destacaram-se com relação ao crescimento vegetativo das plantas no final do período experimental. Não ocorreram diferenças significativas com relação às características dos frutos produzidos em areia, cepilho e solo agricultável. Porém, o tratamento contendo o substrato cepilho proporcionou uma menor severidade da podridão gomosa destacando-se em relação aos demais.

\section{CONCLUSÃO}

O substrato cepilho mostra-se como uma boa alternativa para o plantio de meloeiro rendilhado em sistema semihidropônico, pois além de proporcionar características semelhantes aos frutos produzidos nos demais substratos testados, é um material leve e prático para se manusear, garantindo ao produtor melhor praticidade no momento de instalação da cultura e também remoção de plantas sintomáticas.

\section{REFERÊNCIAS}

\section{AGRIANUAL 2015: Anuário da} agricultura brasileira. São Paulo: FNP, Consultoria e Comércio, 2014. 355- 358p.

ANDRIOLO, J.L.; DUARTE, T.S.; LUDKE, L.; SKREBSKY, E.C. Caracterização e avaliação de substratos para o cultivo do tomateiro fora do solo. Horticultura Brasileira, Brasília, v. 17, n. 3, p. 215-219, nov., 1999.

ARAUJO, J. A. C.; GUERRA, A. C; DURIGAN, J. F. Efeito da adubação orgânica e mineral em cultivares de melão sob condições de casa de vegetação. Revista

Brasileira de Engenharia Agrícola e Ambiental, Campina Grande, v.3, n.1, p.2629, jan-abr. 1999.

AVILA, V. S.; COSTA, C. A. F.; DE FIGUEIREDO, E. A. P.; ROSA, P. S., DE OLIVEIRA, U.; ABREU, V. M. N. Materiais alternativos, em substituição à maravalha como cama de frangos. Comunicado Técnico, Embrapa Suínos e Aves, Concórdia - SC, 5f., 2007.

BEZERRA F. C. Produção de mudas de hortaliças em ambiente protegido. Fortaleza, Embrapa Agroindústria Tropical. 22p. (Embrapa Agroindústria Tropical. Documentos, 72). 2003.

BLANCO, F. F.; FOLEGATTI, M. V. Recuperação de um solo salinizado após cultivo em ambiente protegido. Revista Brasileira de Engenharia Agrícola e Ambiental, Campina Grande, v. 5, n. 1, p. 76-80, jan-abr. 2001. 
BRANDAO FILHO, J. U. T, VASCONCELLOS, M. A. S. A cultura do meloeiro. In: GOTO, R., TIVELLI, S. W. Produção de hortaliças em ambiente protegido: condições subtropicais. São Paulo: Fundação Editora da UNESP, 1998, p.161194.

BRUGNARA, E. C. Cama de aviário em substratos para mudas de maracujazeiroamarelo. Revista Brasileira de Agroecologia, Porto Alegre, v.9, n.3, p. 2130, 2014.

CASTOLDI, R.; CHARLO, H. C. O.; VARGAS, P. F.; BRAZ, L. T. Qualidade de frutos de cinco híbridos de melão rendilhado em função do número de frutos por planta.

Revista Brasileira de Fruticultura, Jaboticabal, v. 30, n. 2, p. 455-458, jun. 2008.

CHARLO, H. C. O.; CASTOLDI, R.; VARGAS, P. F.; BRAZ, L. T. Desempenho de híbridos de melão-rendilhado cultivados em substrato. Científica, Jaboticabal, v.37, n. 1, p.16-21, 2009.

CHARLO, H. C. O.; CASTOLDI, R.; VARGAS, P. F.; BRAZ, L. T. Desempenho de híbridos de melão-rendilhado cultivados em substrato. Científica, Jaboticabal, v. 37, n. 1, p. 16-21, 2009.

CHARLO, H. C. O.; GALATTI, F. S.; BRAZ, L. T.; BARBOSA, J. C. Híbridos experimentais de melão rendilhado cultivados em solo e substrato. Revista Brasileira de Fruticultura, Jaboticabal, v. 33, n. 1, p. 144-156, Mar. 2011.

FACTOR, T. L. Produção de melão rendilhado em ambiente protegido, inverno primavera, na região de Jaboticabal.

Horticultura Brasileira, Brasília, v. 18, n. 3, p. 201-202, jul. 2000.

FILGUEIRA F. A. R. Novo manual de olericultura: agrotecnologia moderna na produção e comercialização de hortaliças. Viçosa: UFV, 421 p, 2008.
GASPAROTTO, F.; VIDA, J. B.;

TESSMANN, D. J.; BONALDO, S. M.;

AGUIAR, R. L.; PENHARBEL, M. P.

Eficiência de métodos para detecção de

Didymella bryoniae associado a sementes de híbridos de meloeiros nobres. Acta

Scientiarum. Agronomy, Maringá, n. 31, v. 3, p. 397-402, Set. 2009.

GASPAROTTO, F.; VIDA, J.B.; TESSMANN D. J.; ALVES, T. C. A. Infecção Latente de Didymella bryoniae em meloeiro nobre. Summa Phytopathologica, Botucatu, v. 37, n.1, p. 62-64, 2011.

KUROZAWA, C.; PAVAN, M. A.; REZENDE, J. A. M. Doenças das Cucurbitáceas. In: KIMATI, H.; AMORIM, L.; REZENDE, J. A. M.; FILHO, A. B.; CAMARGO, L. E. A. Manual de fitopatologia: doenças das plantas cultivadas. 4. ed. v.2, São Paulo: Agronômica Ceres, 2005. Cap. 32, p. 293-303.

MARAGNO, E. S.; TROMBIN, D. F.; VIANA, E. O uso da serragem no processo de minicompostagem. Engenharia sanitária e ambiental, v.12, n.4, p.355-360, out./dez. 2007.

MELO, D. M.; CASTOLDI, R.; CHARLO, H. C. O.; GALATTI, F. S.; BRAZ, L. T. Produção e Qualidade De Melão Rendilhado Sob Diferentes Substratos Em Cultivo Protegido. Revista Caatinga, Mossoró, v. 25, n.1, p. 58-66, jan./mar. 2012.

MELO, D. M.; CHARLO, H. C. O.; CASTOLDI, R.; BRAZ, L. T. Dinâmica do crescimento do meloeiro rendilhado 'Fantasy' cultivado em substrato sob ambiente protegido. Biotemas, Florianopolis, v. 27, n. 2, p. 19-29, jun. 2014.

PADUA, J. G.; BRAZ, D. A.; BANZATTO, S. A. L.; GUSMÃO, M. T. A. Net melon cultivars productivity under different cultivation systems, during summer and winter. Acta Horticulturae, Piracicaba, v. 607, n. 01, p. 83-89, jan./fev. 2003. 
PADUAN, M. T.; CAMPOS, R. P.; CLEMENTE, E. Qualidade dos frutos de tipos de melão, produzidos em ambiente protegidos. Revista Brasileira de

Fruticultura, Jaboticabal, v. 29, n. 3, p. 535539, jul./set. 2007.

PELIZZA, T. R.; SILVEIRA, F. N.; MUNIZ, J.; ECHER, A. H. B.; MORSELLI, T. B. G.

A. Produção de mudas de meloeiro amarelo, sob cultivo protegido, em diferentes

substratos. Revista Ceres, Viçosa, v. 60, n.2, p. 257-261, mar./abr. 2013.

\section{PENHARBEL, M. P. Podridão gomosa}

(Didymella bryoniae) em meloeiro cultivado em ambiente protegido: efeito de sistemas de cultivo e de fungicidas. 2011. $65 \mathrm{f}$. (Mestrado em Agronomia: Área de Concentração em Proteção de Plantas) Universidade Estadual de Maringá, Maringá, 2011.

RIZZO, A. A. N.; BRAZ, L. T. Desempenho de linhagens de melão rendilhado em casa de vegetação. Horticultura Brasileira, Brasília, v.22, n.4, p.784-788, out./dez. 2004.

RIZZO, A. A. N.; CHAVES, F. C. M.; LAURA, V. A.; GOTO, R. Avaliação de métodos de enxertia e porta-enxertos para melão-rendilhado. Horticultura Brasileira, Brasília, v.22, n.4, p.808-810, out./dez. 2004.

SANTIAGO, A. R.; ANDRADE A. M. Carbonização de resíduos do processamento mecânico da madeira de eucalipto. Ciência Florestal, Santa Maria, v.15, n.1, p.1-7, jan./mar. 2005.

SCHNEIDER, C. F., SCHULZ, D. G., LIMA, P. R., \& JÚNIOR, A. C. G. Formas de gestão e aplicação de resíduos da cana-de-açúcar visando redução de impactos ambientais. Revista Verde de Agroecologia e Desenvolvimento Sustentável, v.7, n.5, p.08-17, dez. 2013.
SILVA, P. S. L.; SÁ. W. R.; MARIGUELE, K. H.; BARBOSA, A. P. R.; OLIVEIRA, O. F. Distribuição do teor de sólidos solúveis totais em frutos de algumas espécies de clima temperado. Revista Caatinga, Mossoró, v. 15, n. 1, p. 19-23, jan./mar. 2002.

SILVA, G. B. P.; BARROS, G. L.; SILVA, A. R. F.; MEDEIROS, P. V. Q. Emergência e desenvolvimento inicial de melão amarelo (Cucumis melo L.) usando diferentes substratos. Revista Agrarian, v.6, n.21, p.358-362, jul./set. 2013.

SOUZA, V. R. F.; RODRIGUES, B. H.; ATHAYDE SOBRINHO, C.; COELHO, E.F.; VIANA, F. M. P.; SILVA, P.H.S. Cultivo do meloeiro sob fertirrigação por gotejamento no meio-norte do Brasil. Teresina: EMBRAPA Meio Norte, 1999. 68 p.(Circular Técnica).

VARGAS, P.F.; CASTOLDI, R.; CHARLO, H.C.O.; BRAZ, L.T. Qualidade de melão rendilhado (Cucumis melo L.) em função do sistema de cultivo. Ciência e

Agrotecnologia, Lavras, v. 32, n.1, p.137142, fev. 2008a.

VARGAS, P. F.; CASTOLDI, R.; CHARLO, H. C. O.; BRAZ, L. T. Desempenho de cultivares de melão rendilhado em função do sistema de cultivo. Horticultura Brasileira, Brasília, v. 26, p. 197- 201, abr./jun. 2008b.

VIDA, J.B. Manejo de doenças em cultivos protegidos. In: Brandão Filho, J.U.T., Contiero, R.L.; Andrade, J.M.B. Cultivo protegido: Encontro de Hortaliças da Região Sul, 9., Encontro de Plasticultura da Região Sul, 6. Anais. Maringá, p. 25-30, 1994.

VIDAURRE, G. B.; SILVA, A. N.; ROCHA, J. D. S.; BRITO, E. O. Produção de chapas de partículas de madeira de duas espécies nativas da Mata Atlântica e suas combinações.

Ciência Florestal, Santa Maria, v.14, n.1, p.235-242, jun. 2004. 